\title{
ANALISIS FRAMING BERITA PARIWISATA PADA TELEVISI LOKAL: STUDI KASUS JOGJA TV DI YOGYAKARTA DAN AGROPOLITAN TV DI JAWA TIMUR
}

\author{
Eka Yonavilbia \\ Institut Ilmu Sosial dan Manajemen STIAMI \\ Ekagagak2013@gmail.com
}

\begin{abstract}
Abstrak. Tujuan utama penelitian ini adalah untuk mengetahui kecenderungan ideologi pembingkaian berita pariwisata-idealisme atau komersialisme, yang disiarkan di dua TV lokal; Jogja TV di Yogyakarta dan Agropolitan TV di Jawa Timur. Studi media ini dilakukan dengan menggunakan metode Analisis Framing R Etman terhadap 16 berita lokal dan satu berita non lokal yang disiarkan pada bulan Agustus 2009. Hasil penelitian menunjukkan ada perbedaan ideologi pembingkaian berita lokal pariwisata yang disiarkan kedua TV lokal tersebut. Jogja TV lebih cenderung kepada ideologi komersialisme untuk mendukung promosi pihak swasta sedangkan Agropolitan TV lebih cenderung kepada ideologi idealisme. Walaupun demikian pada program berita non lokal Jogja TV, redaktur membingkai berita pariwisata mengarah pada ideologi idealisme sebagai perwujudan tanggung jawab sosial stasiun TV lokal tersebut.
\end{abstract}

Kata Kunci: berita pariwisata, TV lokal, idealisme dan komersialisme .

Abstract. The main research objective is to understand the tendency of of news framing ideology idealism or commercialism of two local TV, Jogja TV and Agropolitan TV. This media study was carried out using Etman's framing analysis. method concerning 16 local news and one non-local news broadcasted on August 2009. The research results showed that there were the ideological differences of tourism local news framing broadcasted in the both local TV.Jogja TV more inclined to commercialism as promotion on local tourism managed by private company. Meanwhile Agropolitan TV tended to idealism. Regarding the non-local program of tourism, the Jogja TV' editors inclined to idealism as part of social responsibility of local TV stations.

Keywords: tourism news, lokal TV, idealism, commercialism

Sepuluh stasiun televisi swasta nasional berada di Jakarta memberi warna ketidak seimbangan siaran program pembangunan. Ketidakseimbangan siaran sepuluh televisi swasta tersebut melalui penyeragaman acaraacara yang disetting dan ditayangkan di Jakarta serta juga disiarkan di daerah-daerah. Hal ini dilatarbelakangi adanya kepentingankepentingan pragmatisme bisnis dari kapitalisme pemilik televisi swasta. (Anonim,2006).

Era otonomi daerah memberikan perkembangan dan kemunculan di antaranya kedua televisi lokal Jogja TV diYogyakarta dan Agropolitan TV Batu, Malang di Jawa Timur. Kehadiran kedua televisi lokal tersebut dapat mengurangi sentralisme informasi dan bisnis yang merujuk pada siaran televisi swasta nasional di Jakarta.. Kedua televisi tersebut bermanfaat untuk memenuhi kebutuhan informasi pada masyarakat di dua daerah tersebut. (Cakram,2005).

Begitu pula dalam menganalisis teks berita di televisi lokal menekankan pada berita idealisme yaitu berita yang dimuat televisi lokal yang ditujukan untuk kepentingan publik dalam rangka peningkatan kondisi sosial dan budaya, sedangkan berita komersialisme yaitu berita yang dimuat televisi lokal yang ditujukan untuk kepentingan peningkatan keuntungan usaha industri media, perusahan swasta dan Badan Usaha Milik Negara (BUMN). 
Studi media ini lebih menekankan berita pariwisata daripada berita pertanian, pendidikan, dan budaya di kedua televisi lokal. Hal ini dilatarbelakngi karena berita pariwisata diperlukan untuk mengangkat dan menggali potensi lokal dalam sektor pariwisata di dua daerah. Dengan demikian potensi lokal pariwisata di dua daerah tersebut bisa diketahui oleh masyarakat lokal, daerah lain dan pemerintah pusat.

Penelitian ini menggunakan analisis framing $\mathrm{R}$ Etman menekankan pada proses

Berdasarkan permasalah penelitian sebagai berikut :

1. Bagaimana kecenderungan frame berita lokal yang berkembang di dua televisi lokal Jogja TV di Yogyakarta, dan Agropolitan TV, Jawa Timur?

2. Bagaimana kecenderungan frame berita non lokal yang berkembang di televisi lokal. Jogja TV di Yogyakarta?

\section{Kerangka Pemikiran}

Penelitian ini secara garis besar bertujuan untuk mengkaji pengaruh ideologi pada redaktur dan pengelola media di dua televisi lokal Jogja TV di Yogyakarta, dan Agropolitan TV, Batu, Malang, Jawa Timur dan keseimbangan frame berita lokal, idealisme dan non lokal, komersialisme dapat membawa dampak positif dan negatif pada masyarakat lokal.Tujuan penelitian secara rinci sebagai berikut : (1).Untuk mengidentifikasi kecenderungan frame berita yang berkembang di dua televisi lokal Jogja TV di Yogyakarta, dan Agropolitan TV, Batu, Malang , Jawa Timur. (2).Untuk mengetahui latar belakang frame berita yang berkembang di dua televisi lokal tersebut.

\section{Konsep Komersialisme dan Idealisme dalam Frame Berita Siaran Televisi Lokal}

Dalam pembangunan, televisi lokal perlu menggembangkan teks berita yang memiliki konsep keseimbangan aspek komersialisme dan idealisme. Tujuan konsep keseimbangan televisi lokal tersebut agar dapat memenuhi tuntutan dan kebutuhan masyarakat lokal.

Untuk itu, ada tiga konsep komersialisme dan idealisme pada televisi seleksi dan penonjolan berita untuk menarik perhatian pemirsa dan mengetahui ideologi/ latar belakang pengelola maupun redaktur terhadap realitas frame berita lokal pariwisata di dua televisi lokal. (Eriyanto. 2007)

Penelitian yang dilakukan memspesifikasikan frame berita lokal dan non lokal pariwisata di dua televisi lokal Jogja TV dan Agropolitan TV, Batu, Jawa Timur. Hal ini dilatarbelakangi visi misi dua daerah tersebut menekankan basis pariwisata.

lokal yaitu (1).idealisme dalam frame berita siaran televisi lokal, (2).komersialisme dalam frame berita siaran televisi lokal dan (3). keseimbangan idealisme dan komersialisme dalam frame berita siaran televisi lokal.

Ketiga konsep komersialisme dan idealisme pada televisi lokal diharapkan dapat merespon tuntutan masyarakat lokal tersebut sebagai berikut:

1) Konsep Idealisme dalam Frame Berita Siaran Televisi Lokal

Konsep idealisme jika televisi lokal mampu mengangkat aspek lokalitas yang ditujukan untuk kepentingan publik dalam rangka peningkatan kondisi sosial dan budaya masyarakat lokal (Setiawan,2008). Bila televisi lokal menekankan pada frame berita idealisme, maka frame berita tersebut akan membawa dampak positif pada komunikan lokal.

2) Konsep Komersialisme dalam Frame Berita Siaran Televisi Lokal

Konsep komersialisme menekankan jika orientasi pengelola dan redaksi televisi lokal hanya mempertimbangkan pada untuk kepentingan peningkatan keuntungan usaha industri media, perusahan swasta dan Badan Usaha Milik Negara (BUMN) (Rahayu, 2008). Bila televisi lokal menekankan pada frame berita komersialisme, maka frame berita tersebut akan membawa dampak negatif pada komunikan lokal.

3) Konsep Keseimbangan Idealisme dan Komersialisme dalam Frame Berita Siaran Televisi Lokal 
Konsep keseimbangan aspek idealisme dan komersialisme menekankan jika televisi lokal pengelola dan redaktur televisi lokal bersandar pada keseimbangan yang ditujukan untuk kepentingan publik dalam rangka peningkatan kondisi sosial dan budaya masyarakat lokal dan kepentingan peningkatan keuntungan usaha industri media, perusahan swasta dan Badan Usaha Milik Negara (BUMN). (Hasan,2008).

\section{Konsep Analisis Teks Berita Siaran Televisi Lokal}

Ada enam konsep analisis teks berita siaran televisi lokal dan satu hubungan konsep analisis framing Etman dengan penelitian ini, di antaranya adalah analisis Semiotik, analisis Wacana, konsep analisis framing Gamson dan Modigliani, konsep analisis framing Zhongdang Pan dan Gerald M. Kosicki, konsep analisis framing Murray Edelman, konsep analisis framing Robert N. Etman, dan hubungan konsep analisis framing Etman dalam penelitian ini dijelaskan sebagai berikut:

\section{1) Konsep Analisis Semiotik (Semiotic Analysis)}

Dalam menganalisis teks berita digunakan analisis semiotik (semiotic analysis). Analisis.Semiotik adalah ilmu yang mempelajari tanda (sign) terutama pada sistem-sistem, aturanaturan, konvensi-konvensi dalam kebudayaan dan masyarakat yang memungkinkan tanda-tanda tersebut mempunyai arti dalam mengungkapkan pemikiran penulis (Preminger,2001). Analisis semiotik dapat meneliti teks berita, di mana tanda-tanda terkodifikasi dalam sebuah sistem televisi lokal. Sedangkan kelemahan analisis semiotik adalah informasi teks berita yang tidak dapat diperoleh apabila kita hanya mengandalkan analisis semiotik ini. Konsep analisis semiotik tidak sesuai digunakan dalam rangka menganalisis teks berita di kedua televisi lokal.

\section{2) Konsep Analisis Wacana (Discourse Analysis)}

Analisis wacana adalah lebih bisa melihat makna yang tersembunyi dari suatu teks berita di televisi lokal (Eriyanto, 2008) Melalui analisis wacana bukan hanya mengetahui isi teks berita, tetapi juga bagaimana pesan itu disampaikan. Lewat kata, frase, kalimat, dan sebagainya. Analisis wacana menekankan pada teks berita yang dianalisis pada pesan latent (tersembunyi), karena makna suatu pesan tidak bisa hanya ditafsirkan sebagai apa yang tampak nyata dalam teks berita di televisi lokal harus dianalisis dari makna yang tersembunyi. Namun analisis wacana ini belum bisa menganalisis teks berita di dua televisi lokal ini. Konsep analisis wacana tidak sesuai digunakan dalam rangka menganalisis teks berita di kedua televisi lokal Jogja TV dan Agropolitan TV.

3) Konsep Analisis Framing Gamson dan Modigliani

Konsep Analisis Framing Gamson dan Modigliani adalah cara pandang sebagai cara bercerita atau gugusan ide-ide yang terorganisir sedemikian rupa dan menghadirkan konstruksi makna peristiwa-peristiwa yang berkaitan dengan objek suatu wacana.

Analisis framing Gamson dan Modigliani menitikberatkan pada struktur analisis menjadi tiga bagian :

a. Media package (kemasan media) merupakan asumsi bahwa berita memiliki konstruksi makna.

b. Core frame (bingkai inti) merupakan gagasan sentral.

c. Condensing symbol (simbol hasil pencermatan) merupakan hasil pencermatan terhadap perangkat simbolik (framing device / perangkat framing dan reasoningdevice/perangkat penalaran). 
Eka Yonavilbia, Analisis Framing Berita Pariwisata Pada Televisi Lokal: Studi Kasus Jogja TV...

d. Perangkat framing menekankan pada (Framing Devices) Metthaphors adalah perumpamaan dan pengandaian, Catcpharase adalah perangkat berupa jargon-jargon atau slogan, Exemplaar adalah uraian untuk membenarkan perpektif, Depiction adalah leksikon untuk melebeli sesuatu Visual Image adalah perangkat dalam bentuk gambar, grafis dan sebagainya dan perangkat penalaran (Reasoning Devices) Root merupakan analisis kausal atau sebab akibat, Appeals

to principle merupakan premis dasar, klaim moral, Consequence merupakan efek dan konsep.

Namun analisis framing Gamson dan Modigliani belum dapat menganalisis teks berita di dua televisi lokal dan hanya menekankan pada konstruksi makna. Konsep analisis framing Gamson dan Modigliani tidak sesuai digunakan dalam penelitian ini.

\section{4) Konsep Analisis Framing Zhongdang} Pan dan Gerald M. Kosicki

Konsep analisis framing Zhongdang Pan dan Gerald M.Koski menekankan pada penonjolan struktur makna atas peristiwa atau mengkonstruksi realitas untuk digunakan oleh wartawan.

Model analisis framing Zhongdang Pan dan Gerald M. Kosicki membagi struktur analisis menjadi empat bagian :
a. Sintaksis adalah cara wartawan menyusun berita. Headline merupakan berita yang dijadikan topik utama oleh media, .lead, latar informasi, kutipan, e.sumber, pernyataan dan penutup.

b. Skrip adalah cara wartawan mengisahkan fakta. Struktur skrip memfokuskan pada kelengkapan berita $5 \mathrm{~W}+1 \mathrm{H}$.

c. Tematik adalah cara wartawan menulis fakta. Struktur tematik mempunyai perangkat framing : detail, maksud dan hubungan kalimat, nominalisasi antar kalimat, koherensi, bentuk kalimat, kata ganti, unit yang diamati adalah paragraph dan proposisi.

d. Retoris adalah cara wartawan menekankan fakta. Struktur retoris mempunyai perangkat framing: leksikon/pilihan kata (perangkat ini merupakan penekanan terhadap sesuatu yang penting), grafis, metaphor, pengandaian : unit yang diamati adalah kata, idiom, gambar/foto, dan grafis.

Sedangkan konsep analisis framing Zhongdang Pan dan Gerald M.Koski menitikberatkan penonjolan struktur makna atas peristiwa atau mengkonstruksi realitas untuk digunakan oleh wartawan belum dapat mengungkapkan di dua televisi lokal jika hanya menggunakan analisis framing Zhongdang Pan dan Gerald M.Koski. Konsep analisis framing tersebut tidak juga sesuai digunakan dalam penelitian ini.

5) Konsep Analisis Framing Murray Edelman

Konsep analisis framing Murray Edelman menitikberatkan bagaimana kita membingkai dan mengkonstruksi/menafsirkan realitas. Realitas yang sama bisa jadi akan menghasilkan realitas berbeda ketika realitas tersebut dibangkai atau dikonstruksi dengan cara berbeda.

Sebuah perang bisa disebut sebagai perjuangan suci dapat juga disebut sebagai agresi. Pilihan mana yang diambil tidak hanya berkaitan dengan pilihan kata-kata semata, tetapi menghadirkan realitas sendiri, ketika hadir ditengah khalayak.

Namun konsep analisis framing analisis framing Murray Edelman belum dapat menganalisis di dua televisi lokal ini apabila hanya menggunakan analisis framing Murray Edelman

\section{6) Konsep Analisis Framing Robert N.} Etman 
Konsep analisis framing R. Etman yang paling cocok untuk menganalisis teks berita di dua televisi lokal Jogja TV dan Agropolitan TV. Analisis framing ini menekankan pada :

a. Penyeleksian keseimbangan aspek realitas teks berita di dua televisi lokal.

b. Penempatan yang mencolok di headline berita (bagian depan) yang segera perlu diketahui oleh pemirsa untuk menarik perhatian.

c. Penonjolan frame berita yang sering ditayangkan di dua televisi lokal Jogja TV dan Agropolitan TV.

d. Mengetahui ideologi/ latarbelakang pengelola maupun redaktur terhadap realitas frame berita lokal idealisme maupun non lokal komersialisme di televisi lokal.

e. Skema dari konsep framing Robert N. Entman lebih memfokuskan pada Problem Indentification (Pendefinisian masalah), Causal Interpretation (Sumber atau penyebab masalah), Moral Evaluation (Membuat keputusan moral) dan Treatment Recommendation (Penekanan penyelesaian).

\section{Metode (Methods)}

Metode penelitian yang digunakan dalam penelitian ini adalah mixed method, karena pemerosesan informasi dan pengolahan data dilakukan dalam suatu analisis kuantitatif diikuti dengan kualitatif.

Teknik pelaksanaan penelitian kuantittatif dengan metode penelitian observasi (Nazir,2005) yaitu penelitian yang mengambil data sampel dari suatu populasi frame berita lokal dan non lokal pariwisata di dua televisi lokal.

Sedangkan teknik penelitian kualitatif dilakukan dengan cara mengumpulkan data berdasarkan pendapat redaktur di dua televisi lokal untuk mengungkapkan proses dan makna yang tersembunyi dibalik fenomena rill. (Burhan,2007)

\section{Hasil Penelitian dan Pembahasan (Results and Discussion)}

\section{1) Analisis Framing R Etman}

Analisis Framing $\mathrm{R}$ Etman menyajikan frame berita lokal dan non lokal disiarkan melalui program Seputar Jogja dan Agropolitan News. Sedangkan Frame non lokal yang disiarkan melalui program Suluh Indonesia. Analisis Framing pariwisata menyajikan dua bagian yaitu bagian pertama Analisis Framing berita lokal pariwisata Seputar Jogja dan Agropolitan News, sedangkan bagian kedua Analisis Framing berita non lokal pariwisata Suluh Indonesia sebagaimana berikut :

\section{a. Analisis Framing Berita Lokal Pariwisata Seputar Jogja dan Agropolitan News.}

Analisis Framing Berita Lokal Pariwisata Seputar Jogja

Teks berita Analisis Framing Stand batik Lawasan dalam rangka pameran Tecraft 2009 di Jogja Expo Center sebagai berikut :

Jogja TV Batik Lawasan sering dianggap sebagai batik yang tidak menarik dan lusuh. Padahal batik Lawasan memiliki motif yang khas dan serta memiliki makna tertentu.Batik Lawasan ditinggalkan masyarakat pada waktu dahulu. Kini batik tersebut mulai menggeliat kembali. Saat ini masyarakat mulai tertarik dengan motif-motif batik Lawasan. Hal ini menjadi peluang bagi pelaku usaha untuk menyediakan batik Lawasan. Salah satu stand batik Lawasan dalam pameran Tecraft 2009 di Jogja Expo Center yang berlangsung mulai 12 hingga 16 Agustus 2009. Stand Lawasan Batico yang juga milik putri Sultan Hamengkubowono X yakni Gusti Raden Ajeng Nurastuti Wijareni menghadirkan beragam batik Lawasan dengan motif seperti Kawung dan Parang. Dalam pameran tersebut, batik Lawasan dijual seharga 50 ribu rupiah. (Jogja TV, Seputar Jogja, Sabtu,15/8/2009). 
Eka Yonavilbia, Analisis Framing Berita Pariwisata Pada Televisi Lokal: Studi Kasus Jogja TV...

Mengacu pada teks di atas, analisis Framing R. Etman meliputi: frame dalam hal ini adalah tentang stand batik Lawasan dalam rangka pameran Tecraft 2009 di Jogja Expo Center. Define problem dalam teks berita tersebut adalah masyarakat mulai tertarik dengan motif Batik Lawas. Diagnose cause yaitu tentang batik Lawas merupakan peluang usaha. Make moral judgment dari teks berita adalah redaktur lebih menekankan kepentingan swasta dan ideologi pemberitaan komersialisme. Sedangkan treatment recommendation dalam teks berita tersebut tidak ada.

Berdasarkan uraian di atas, dapat disimpulkan bahwa Analisis Framing frame pariwisata Seputar Jogja lebih menekankan komersialisme daripada idealisme. Dalam hal ini berarti bahwa redaktur televisi lokal tersebut lebih memperhatikan pihak swasta dan BUMN.

\section{Analisis Framing Berita Lokal Pariwisata Agropolitan News}

Teks berita Analisis Framing: Batu Flora Festival 2009 dalam rangka HUT RI ke 64 di kota wisata Batu berikut:

Batu ATV Kemeriahan puncak HUT RI ke 64 di Kota Wisata Batu sungguh sangat terasa dengan hadirnya tradisi baru Festival Bunga atau Batu Flora Festival. Hampir seluruh elemen masyarakat Kota Wisata Batu menyampaikan diri untuk menyaksikan kemeriahan Batu Flora Festival 2009. Batu Flora Festival sebagai puncak kegiatan peringatan tujuh belasan di Kota Batu kemarin cukup mendapat respon dari ribuan masyarakat Kota Batu yang ingin menyaksikan keunikan serta keindahan kreasi yang ditampilkan dalam Festival Bunga tampak hampir seluruh masyarakat Batu memadati seluruh rute jalan yang dilewati oleh peserta festival dengan rela berdesakdesakan hanya untuk dapat melihat penampilan beraneka kreasi yang disajikan dalam puncak kegiatan HUT tahun ini.Batu Flora festival diikuti 43 peserta yang berasal dari masyarakat umum, instansi pemerintah, pengelola hotel,pengelola wisata serta lembaga sekolah dengan menampilkan berbagai kreasi. Penyelenggaraan Batu Flora Festival tahun ini terlihat lebih menarik baik dari segi penyajian maupun beraneka kreasi yang ditampilkan. (ATV, Agropilitan News, Rabu,19/8/2009)

Berkaitan dengan teks di atas, Analisis Framing R. Etman dari teks berita ini meliputi: frame yaitu tentang Batu Flora Festival 2009 dalam rangka HUT RI ke 64 di kota wisata Batu. Untuk define problem dalam hal ini adalah respon hampir seluruh elemen masyarakat Kota Batu menyaksikan kemeriahan acara tersebut. Kemudin diagnose cause dalam teks berita yaitu tentang keunikan dan keindahan kreasi yang ditampilkan dalam festival flora. Make moral judgment pada teks berita tersebut yaitu redaktur lebih menekankan kepentingan masyarakat. Untuk ideologi pemberitaannya lebih menekankan idealisme. Treatment recommendation dalam teks berita tersebut tidak ada.

Berdasarkan uraian di atas, dapat disimpulkan bahwa Analisis Framing frame pariwisata Agropolitan News lebih menekankan idealisme daripada komersialisme. Dalam hal ini berarti bahwa redaktur televisi lokal tersebut lebih menekankan kepentingan masyarakat.

Dengan demikian dari penjelasan dua televisi lokal dapat disimpulkan bahwa ideologi pemberitaan sering muncul pada tayangan Seputar Jogja dan Agropolitan News pada frame berita pariwisata.

Analisis Framing lebih menekankan komersialisme daripada idealisme dilihat dalam persentase Tabel 1 sebagaimana berikut: 
Tabel 1

Rekapitulasi Persentase Ideologi Pemberitaan Frame Berita Pariwisata Jogja TV dan Agropolitan TV, 2009

\begin{tabular}{|c|l|c|}
\hline NO & \multicolumn{1}{|c|}{ KRITERIA BERITA } & PERSENTASE \\
\hline 1 & Idealisme & 44 \\
\hline 2 & Komersialisme & 56 \\
\hline & Total Persentase Idealisme dan Komersialisme & 100 \\
\hline
\end{tabular}

Sumber : Analisis Data Primer $(n=16)$

\section{b. Analisis Framing Berita Non Lokal Pariwisata Suluh Indonesia \\ Program Berita Non Lokal Suluh} Indonesia yang disiarkan oleh Jogja TV menyajikan berita mengenai pariwisata. Teks berita pariwisata tentang "Korban Padusan Pantai Trisik dan Glagah Kulonprogo" berikut:

Jogja TV Hingga Sabtu Siang, dua korban yang terseret ombak pantai Trisik dan Glagah Kulonprogo belum ditemukan hingga kini. Tim Sar kedua pantai masih aktif melakukan penyisiran di sepanjang pantai, namun untuk pencarian ke tengah laut tidak memungkinkan, akibat terbatasnya peralatan serta tingginya gelombang untuk melakukan padusan Jumat Sore lalu.Tim Sar Glagah dan Trisik Kulonprogo hingga Sabtu Siang masih melakukan penyisiran di sepanjang pantai untuk mencari dua korban hilang terseret ombak pada Jumat Sore. Pencarian akan dilakukan selama empat hari kedepan dengan menggerahkan seluruh personel yang ada serta bantuan dari Tim Sar Waduk Sermo.Menurut Koordinator Sar Wilayah 5, Sugeng, untuk pencarian ke tengah laut tidak memungkinkan, karena gelombang tinggi dan peralatan kurang dimiliki. Pihaknya juga telah berkoordinasi dengan Sar Kabupaten Bantul dalam rangka melihat pergerakan arus menuju kearah timur. Bila kondisi gelombang mulai normal, Sar juga akan meminta bantuan nelayan yang melaut, meskipun harapannya cukup kecil.Dia menuturkan pula dua korban hilang adalah Zaenab, warga Ngabean Secang Magelang, berumur 18 tahun yang terseret ombak di pantai Glagah pada pukul 14.45, sedangkan di pantai Trisik, Topo Rifai, warga Bendo Ngetakrejo Lendah Kulonprogo berumur 17 tahun yang terseret ombak sekitar pukul 16.30. Pada hari yang sama. Keduanya terseret ombak saat melakukan padusan menjelang datangnya bulan ramadhan Jumat kemarin. (Jogja TV, Suluh Indonesia, Sabtu, 22/8/2009)

Berkenaan dengan teks tersebut, analisis Framing R. Etman meliputi: Frame korban padusan pantai Trisik dan Glagah Kulonprogo. Define problem dalam teks berita tersebut adalah tingginya ombak dan peralatan terbatas. Diagnose cause yaitu tentang dua korban padusan terseret ombak pantai Trisik dan Glagah Kulonprogo belum ditemukan. Make moral judgment yaitu redaktur menekankan kepentingan masyarakat. Ideologi pemberitaannya adalah idealisme. Sedangkan untuk treatment recommendation dalam teks berita tersebut tidak ada.

Berdasarkan uraian analisis Framing R Etman diatas, frame berita non lokal pariwisata dalam program Suluh Indonesia di Jogja TV disimpulkan bahwa ideologi pemberitaan yang muncul pada tayangan Suluh Indonesia lebih menekankan idealisme disajikan dalam persentase Tabel 2 sebagaimana berikut: 
Eka Yonavilbia, Analisis Framing Berita Pariwisata Pada Televisi Lokal: Studi Kasus Jogja TV...

Tabel 2

Rekapitulasi Persentase Ideologi Pemberitaan Frame

Berita Non Lokal Pariwisata

Jogja TV, 2009

\begin{tabular}{|c|l|c|}
\hline NO & \multicolumn{1}{|c|}{ KRITERIA BERITA } & $\begin{array}{c}\text { JENIS BERITA } \\
\text { PARIWISATA }\end{array}$ \\
\hline 1 & Idealisme & 100 \\
\hline 2 & Komersialisme & 0 \\
\hline & Total Persentase Idealisme dan Komersialisme & 100 \\
\hline
\end{tabular}

Sumber : Analisis Data Primer $(n=1)$

Tabel 2 dapat diketahui bahwa frame berita pariwisata untuk ideologi pemberitaan idealisme sebesar 100\%, sedangkan komersialisme masingmasing $0 \%$.

Penilaian tersebut didukung oleh pernyataan berikut: "Program Suluh Indonesia tetap memprioritaskan yang berkenaan dengan visi misi organisasi meskipun berita non lokal",(Wawancara dengan Bapak Andhi Wisnu Wicaksana, Penanggung Jawab Program dan Pemberitaan Jogya TV, tanggal 28 Oktober 2009).

\section{Uji T Test}

Uji $\mathrm{T}$ Test ini menggunakan program SPSS 15.00 for Windows dan menggunakan data yang berskala interval dan rasio. Model Pengujian yang digunakan dari $\mathrm{T}$ Test adalah pengujian dua sampel idealisme dan komersialisme tidak berhubungan (Independent Sampel T Test). Selain itu, pengujian menggunakan uji dua sisi dengan tingkat signifikan $\alpha=5 \%$. Tingkat signifikan berarti mengambil resiko salah dalam mengambil keputusan untuk menolak hipotesis yang benar sebanyak 5\% atau 0,05 adalah ukuran standar yang sering digunakan dalam penelitian.

Uji T Test Frame Berita Lokal Seputar Jogja dan Agropolitan News dan Berita Non Lokal Suluh Indonesia

Bagian Uji $\mathrm{T}$ Test ini menyajikan dua bagian. pertama menjelaskan Uji $\mathrm{T}$ Test frame berita lokal Seputar Jogja di Jogja TV dan Agropolitan News di Agropolitan TV, dan bagian kedua Uji T Test Frame berita non lokal dalam program berita Suluh Indonesia di Jogja TV.

\section{Frame Berita Lokal Seputar Jogja dan} Agropolitan News

Hasil penelitian menyajikan frame berita lokal pariwisata untuk program Seputar Jogja dan Agropolitan News digunakan T Test pada Tabel 3. Hasil analisis Uji Ttest dua sampel indepeden terhadap frame berita lokal pariwisata pada program Seputar Jogja dan Agropolitan News dapat disajikan pada Tabel 3 sebagaimana berikut:

Tabel 3

Hasil Analisis Uji T-test Dua Sampel Indepeden Terhadap Frame Berita Lokal Pariwisata Pada Program Seputar Jogja dan Agropolitan News, 2009

\begin{tabular}{|c|l|c|c|c|}
\hline No & \multicolumn{1}{|c|}{ Ideologi } & n & $\begin{array}{c}\text { Nilai Rata-Rata Terhadap } \\
\text { Frame Berita Lokal }\end{array}$ & t-hitung \\
\hline 1 & Idealisme & 7 & 0,4375 & 0,690 \\
\hline 2 & Komersialisme & 9 & 0,5625 & \\
\hline \multicolumn{2}{l|}{$\alpha=5 \%, \mathrm{~N}=16, \mathrm{df}=14, \mathrm{t}$ tabel $=2,145$} & \\
\hline
\end{tabular}

Sumber : Analisis Data Primer 
Dari tabel 3 dapat diketahui bahwa nilai $\mathrm{t}$ hitung sebesar 0,690< t tabel sebesar 2,145. Hal ini berarti hipoetsis $1 \mathrm{H}_{0}$ diterima, sehingga $\mathrm{H} a$ yang berbunyi jumlah berita aspek idealisme lebih banyak daripada komersialisme tidak terbukti.

Frame Berita Lokal Pariwisata Seputar Jogja

Menurut Joseph Pulitzer (1972) mengkhawatirkan ketika komersialisme telah menjadi tujuan utama dalam industri media, maka saat itu media hilang kekuatan idealisme berupa moral dan etika. Komersialisme ditujukan untuk kepentingan swasta dan BUMN. Selanjutnya menurut Kovach dan Tom (2001), hasil penelitiannya di Ameruka Serikat menunjukkan televisi mengarahkan sasaran liputan terutama untuk kelompok elit dan tidak memperdulikan sebagian besar masyarakat. Untuk itu, liputan televisi di negara tersebut lebih menekankan komersialisme daripada idealisme.

Hasil penelitian mendeskripsikan bahwa frame berita pariwisata di Jogja TV lebih menekankan deologi pemberitaan komersialisme daripada idealisme. Hal ini dilatarbelakangi Jogja TV sering mendapat undangan liputan frame berita pariwisata untuk kepentingan pihak swasta pada bulan Agustus.

Dalam hubungannya dengan komersialisme, seperti dikemukakan oleh Andhi Wisnu Wicaksana (2009) berikut: "Frame berita pariwisata di Seputar Jogja menekankan komersialisme, karena liburan sekolah dan universitas pada bulan Agustus 2009, maka para pengelola pariwisata memiliki kesempatan untuk mempromosikan tempat-tempat pariwisata di Yogyakarta pada siswa dan mahasiswa di Yogyakarta". (Wawancara dengan Bapak Andhi Wisnu Wicaksana, Penanggung Jawab Program dan Pemberitaan Jogya TV, tanggal 28 Oktober 2009).

\section{Frame Berita Lokal Pariwisata Agropolitan News}

Sebaliknya televisi lokal Agropolitan TV menunjukkan bahwa untuk frame berita lokal pariwisata menunjukan bahwa frame berita pariwisata lebih menekankan idealisme daripada komersialisme. Hal ini latarbelakangi visi misi Agropolitan TV dan kota Batu menekankan pariwisata.

Berikut kutipan pendapat yang dikemukakan oleh Redaktur Agropolitan TV M.Syamsul Arif: "Frame berita pariwisata di Agropolitan TV menekankan idealisme karena visi misi kota Batu menekankani objek-objek pariwisata yang berdaya pesona bagi wisatawan lokal, nasional, dan asing ".(Wawancara dengan Bapak, M.Syamsul Arif Koordinator Redaktur Agrdopolitan TV, tanggal 18 Oktober 2009).

Hasil penelitian tersebut diperkuat oleh Jurgen Hubermas (1993), industri media massa televisi lokal seyogianya menekankan filsafat moral dan etika pada frame berita lokal idealisme. Media massa dibentuk sebagai bagian integral dan public sphere (ruangan publik).

\section{Frame Berita Non Lokal Suluh Indonesia}

Untuk membuktikan hipotesis kedua yang berbunyi bahwa diduga frame berita non lokal dalam program berita Suluh Indonesia di Jogja TV jumlah berita aspek komersialisme lebih banyak daripada idealisme digunakan $\mathrm{T}$ Test dua sampel independent. Analisis Uji Ttest dua sampel indepeden terhadap frame berita non lokal pada program Suluh Indonesia tidak dapat dilakukan karena jumlah berita non lokal hanya dua berita yaitu 1 berita pertanian terdiri atas 1 idealisme dan 0 komersialisme, begitu pula 1 berita pariwisata. 1 idealisme dan 0 komersialisme.

Menurut Setiawan (2008), konsep idealisme adalah jika televisi lokal mampu mengangkat aspek lokalitas yang ditujukan untuk kepentingan 
Eka Yonavilbia, Analisis Framing Berita Pariwisata Pada Televisi Lokal: Studi Kasus Jogja TV...

publik dalam peningkatan kondisi sosial dan budaya masyarakat lokal.

Hasil penelitian menunjukkan bahwa dalam hal frame berita non lokal pariwisata Jogja TV yang disiarkan televisi lokal Jogja TV lebih menekankan ideologi pemberitaan idealisme daripada komersialisme. Hal ini dilatarbelakangi Jogja TV tetap mengacu pada visi misi televisi lokal tersebut.

Hal di atas diperkuat oleh Andhi Wisnu Wicaksana (2009) sebagaimana berikut: "Frame berita pariwisata program Suluh Indonesia menekankan idealisme, karena berita tersebut memfokuskan muatan lokal yang memiliki isu-isu yang aktual pada suatu daerah dan ditonton oleh seluruh pemirsa di seluruh Indonesia". (Wawancara dengan Bapak Andhi Wisnu Wicaksana, Penanggung Jawab Program dan Pemberitaan Jogya TV, tanggal 28 Oktober 2009).

Uraian di atas menunjukkan bahwa televisi lokal Jogja TV lebih menekankan frame berita non lokal yang berorientasi pada ideologi pemberitaan idealisme daripada komersialisme yang ditujukan untuk kepentingan publik. Dengan demikian televisi lokal Jogja TV dapat memberikan kontribusi pada frame berita non lokal pariwisata untuk memenuhi kebutuhan informasi pariwisata lokal pada masyarakat lokal dan nasional.

\section{Simpulan dan Saran (Conclusion and Suggestion)}

Berdasarkan hasil analisis dan pembahasan penelitian dapat ditarik kesimpulan sebagai berikut :

1. Frame berita lokal pertanian, pendidikan, dan budaya yang disiarkan di dua televisi lokal Jogja TV dan Agropolitan TV menekankan ideologi idealisme. Berkaitan dengan frame berita lokal pariwisata Jogja TV dan Agropolitan TV ada perbedaan. Frame berita pariwisata Jogja TV lebih memfokuskan komersialisme, sedangkan frame berita pariwisata Agropolitan TV cenderung idealisme. Untuk frame berita non lokal pertanian dan pariwisata Jogja TV mengarah idealisme.

2. Frame berita lokal pertanian Jogja TV dan Agropolitan TV lebih menekankan ideologi pemberitaan idealisme. Dalam pemberitaan ini, Jogja TV dilatarbelakangi oleh keadaan wilayah serta masyarakat Yogyakarta dan sekitarnya yang lebih menekankan pada aspek kehidupan ekonomi yang berbasis pertanian. Untuk televisi lokal Agropolitan TV dilatarbelakangi visi misi Agropolitan TV dan kota Batu adalah pariwisata yang berbasis pertanian.

3. Frame berita pendidikan Jogja TV dan Agropolitan TV lebih menekankan ideologi pemberitaan idealisme. Pemberitaan yang disiarkan Jogja TV berkaitan dengan salah satu pilar dari visi misi Jogja TV dan propinsi Yogyakarta yaitu sebagai kota pendidikan yang mendapat julukan "kota pelajar". Sedangkan Agropolitan TV lebih menekankan idealisme yang dilatarbelakangi karena pada bulan Agustus merupakan tahun ajaran baru dan Agropolitan TV sering mendapat undangan liputan dari Pemerintah Daerah Kota Batu.

4. Frame berita budaya Jogja TV lebih menekankan ideologi pemberitaan idealisme. Dalam pemberitaan ini dilatarbelakangi visi misi Jogja TV untuk terus mengembangkan budaya khas dan unik Yogyakarta dalam siaran di televisi lokal Jogja TV. Selain itu, Yogyakarta merupakan kota dan masyarakat yang berpegang teguh pada budaya lokal.

5. Frame berita pariwisata yang disiarkan oleh televisi lokal Jogja TV dan Agropolitan TV ada perbedaan. Dalam pemberitaan ini Jogja TV lebih menekankan ideologi pemberitaan komersialisme. Hal ini dilatarbelakangi karena pada bulan Agustus Jogja TV sering mendapat undangan untuk 
meliput berita pariwisata guna kepentingan pihak swasta. Sedangkan pemberitaan yang disiarkan oleh Agropolitan TV lebih menekankan ideologi pemberitaan idealisme. Dalam pemberitaan ini dilatarbelakangi oleh visi misi Agropolitan TV dan Kota Batu yang lebih menekankan pariwisata.

6. Frame berita non lokal pertanian Jogja TV lebih menekankan ideologi pemberitaan idealisme. Hal ini dilatarbelakangi Jogja TV tetap memegang teguh visi misi televisi lokal untuk memenuhi kebutuhan informasi pertanian lokal pada masyarakat lokal dan nasional. Begitu pula untuk frame berita non lokal pariwisata Jogja TV lebih menekankan ideologi pemberitaan idealisme. Hal ini dilatarbelakangi karena berita pariwisata dari televisi lokal ini mengacu pada visi misi yang memiliki isu-isu muatan lokal pariwisata yang bersifat nasional

7. Frame berita pertanian, pariwisata, pendidikan dan budaya yang dibingkai oleh redaktur dan disiarkan di dua televisi lokal Jogja TV dan Agropolitan TV lebih memprioritaskan aspek kebutuhan masyarakat dengan mempertimbangkan perintah dari atasan maupun pendapat /keinginan pribadi. Hal ini dilatarbelakangi karena dua televisi lokal merupakan bagian dari masyarakat yang memiliki rasa tanggung jawab moral untuk mengakomodasi kebutuhan informasi pada masyarakat.

Dengan mengacu pada kesimpulan di atas, maka peneliti merumuskan beberapa saran/implikasi penelitian yang dapat dipertimbangkan dan dilaksanakan bagi pihak terkait sebagai berikut:

1. Jogja TV kedepan diharapkan dapat lebih berupaya untuk mempertahankan dan mengembangkan konsistensi pada ideologi pemberitaan idealisme dan komersialisme yang mengacu pada visi misi dan profit lembaga penyiaran tersebut dalam rangka meningkatkan pembangunan di daerah tersebut.

2. Agropolitan TV kedepan perlu dilakukan peningkatkan konsistensinya pada ideologi pemberitaan idealisme agar Agropolitan TV dapat memberikan kontribusi pada masyarakat kota Batu, Jawa Timur.

\section{DAFTAR PUSTAKA}

\section{Buku/Dokumen}

Andersen, Kenneth. 1972. Introduction to communication Theory and Practice. Cumming Pubi Company: Phillippines.

Burhan, Bungin. 2007. Penelitian Kualitatif : Komunikasi, Ekonomi, Kebijakan Publik, Dan Ilmu Sosial Lainnya. Cetakan kesatu, Prenada Media Group.

Cakram. 2005.“Kelola TV Lokal Perlu Idealisme". Edisi Khusus Televisi, Desember 2005.

Eriyanto. 2007. Analisis Framing : Konstruksi, Ideologi dan Politik Media. Cetakan keempat, LKiS Pelangi Aksara : Yogyakarta.

Habermas, Jurgen. 1993. The Structural Transformation of The Publik Sphere An Inquiry into a Category of Bourgeois Society. Translated by Thomas Burger. MIT Press : Cambridge Massachusetts

Hasan, Zaini, 2008. Padang TV dan kearifan Lokal, Surat Kabar Padang Ekpsres (29/8).

Kovach, Bill dan Tom Rosinstiel. 2001. "The Elements of Journalism : What Newspeople Should Know and The Public Should Expect". Amazon.

Nasir, Moh. 2005. Metode Penelitian. Ghalia Indonesia : Jakarta. 
Eka Yonavilbia, Analisis Framing Berita Pariwisata Pada Televisi Lokal: Studi Kasus Jogja TV...

$$
\begin{aligned}
& \text { Preminger, } \\
& \text { Alex, et } \\
& \text { al.(ed).2001."Semiotik (Semiologi)" } \\
& \text { dalam Jabrohim (ed.), } \\
& \text { MetodologiPenelitian Sastra. } \\
& \text { Penerjemah Rahmat Djoko Pradopo, } \\
& \text { Yogyakarta : Hadindita Graha Widia. }
\end{aligned}
$$

Rahayu, 2008. Televisi Swasta Masih Andalkan Hiburan, Hasil Penelitian Pusat Kajian, Media dan Budaya Populer (PKMBP)

\section{Artikel Dalam Internet}

Anonim,2006. "Sepuluh TV Swasta Langgar UU Penyiaran". Diakses dari http://garutkab.go.id/pub/news. (31/8/2009).

Setiawan, Asep 2007. Karakteristik Berita. Dikutip dalam website freejournalist.wordpress.com

Setiawan, Yohanes, Tomy 2008. Visi Misi Suatu Organisasi Media, diakses http ://tomysetiawan.blogspot.com/2008/10/ visi-misi-suatu-oragnisasi-media.html

Tomy, Setiawan Yohanes. 2008. “ Visi Misi Suatu Organisasi Media”. Diakses dari

http://tomysetiawan.blogspot.com/2008 /10/visi-misi-suatu-organisasimedia. htlm. (31/8/2009). 